\title{
Editorial
}

\section{History as tragedy, never as farce: Tracing the long cultural narrative of child protection in England}

\section{Andrew Cooper and Andrew Whittaker}

As parents we hand on the best and worst of ourselves to our children, and much more in between. Philip Larkin's famous poem, best known for its startling opening line 'They fuck you up, your mum and dad' recalls only the damage done, the inter-generational erosion of joy and potential stemming from bad parenting that 'deepens like a coastal shelf'. As a society we create conditions in which different childhoods can be lived out. We say that smacking children is OK, or not. We recognise and respond to the prevalence of sexual abuse and exploitation in ordinary families, or not. We do something about child trafficking, or not. These social conditions evolve, but slowly and ambivalently, suffer reversals of fortune, and vary widely among nation states and across continents. However, if one test of civilised development in a nation were to examine its treatment of child welfare professionals, then Britain, and especially England, would fare badly. Social workers have been taking a public beating in England for 40 years in a manner unknown in any other country, and the haemorrhaging has spread so there is now a crisis in paediatric recruitment and other child medical specialities. Few want to risk their careers against the possibility of a public lynching for failing to ask the right questions about a child who ends up on the mortuary slab a few days later.

This crisis is just one symptom of the long, complex cultural narrative of child maltreatment and child protection work in Britain that has been profoundly shaped by recurrent episodes of moral panic and febrile media scandal mongering, usually centring on individual cases of child death. The Cleveland crisis of 1987 was different, and marked a radical, though highly contested turning point in our recognition of the prevalence of intra-familial child sexual abuse. Moral panics over 'Satanic abuse' followed in its wake, and then the 'recovered memory' wars. The North Wales and Leicestershire 'pindown' inquiries disclosed systematic institutional abuse to be an uncomfortably widespread phenomenon. Child protection policy and practice in Britain is an uneasy settlement between reactions to these events, the pendulum swings of family policy and government ideology, and obstinately ambivalent attitudes towards children and childhood in the wider society.

The Munro Review must be situated within this history and represents the latest attempt to reform the child protection system. The profound problem facing any effort to reform professional practices is that they long ago ceased to be situated within ordinary self-contained social systems. Professional systems in complex societies become increasingly specialised, selfreplicating, or autopoietic as the German sociologist Niklas Luhmann termed 
it. The demands of democratic accountability are in tension with this trend, but for the most part sophisticated professional practices develop according to their own inner logic. But child protection work in Britain has regularly exploded into front-page news, and for two decades the specialised professional system has been a very fragile container for those working inside it. These eruptions have had a further consequence, disclosing the deep existential and social anxieties that child protection work engages with, and protects the rest of the population from having to know too much about. Bluntly, these anxieties concern human sexuality in all its slippery, precarious, destructive manifestations, and death.

\section{The ultimate humiliation of reason}

The paradox is that in exposing this, we are also offered an opportunity to reflect deeply on how our late modern society handles, or fails to handle these more timeless preoccupations. Mostly we have not taken this opportunity. A senior child protection manager one of us (AC) knows worked in an office where a large cabinet contains the files of all the dead and seriously injured children who have been subject to Serious Case Reviews in her area. She told me she had read 26 of these reviews in the last two years. One of them had hit the headlines in a big way, and she described herself as emerging slowly from an organisational climate like a 'pit of death'. Most work with maltreated children is more mundane, and rarely grabs the attention of the wider public. But each story is desperately painful and the professional task of sticking with this pain is well narrated by social worker Becky Hope (Hope 2011). But because of Britain's distinctive policy history all such work is shadowed by a fear of death. Child death tragedies provide a window onto this world, exposing us to what Zygmunt Bauman called 'the ultimate humiliation of reason' (Bauman 1992). He added that 'contingency, accident and fate are deeply resented', and this is how our society has tended to react when confronted by evidence of the torture and death of children.

The great strength of the Munro Review of Child protection is in making a determined effort to re-connect us with a more balanced, and tolerant set of attitudes and responses. However, there are significant obstacles if this is to be achieved and understanding these obstacles requires us to understand the context into which the latest drive to reform England's child protection system has been thrust. In conventional policy terms Every Child Matters (ECM) was new Labour's valiant attempt to re-establish a universalist public policy framework for children and families. Since the Coalition came to power these three words are now outlawed in the public discourse of the Department of Education. In child welfare, as in every other domain, localism and pluralism are the current watchwords. No more central government policy prescription if it can be avoided, no more 'targets and terror', both of which did have radical and largely baleful impacts on the efforts of front line child protection staff over the last decade. 
Social crises around child abuse happen in other countries, with Ireland and Belgium experiencing their Cleveland and North Wales moments in recent years. The radical, innovative Flemish child protection system was rocked to its roots by the Dutroux affair in the 1990s but survived because political leaders and the wider society united in recognising that the deaths of the children involved deserved more, and meant more, than a socially vengeful response provides. But there is a unique, cyclical aspect to Britain's story. For several decades child protection work in this country has seemed like a matter of history repeating itself, never as farce but always - and in many registers as tragedy. This story bears deeper examination than policy makers are accustomed to engage in.

The initial smoke signals from the Munro Review of Child Protection were encouraging. Under new Labour, academics, intellectuals and researchers were relegated to the back benches of policy making, notwithstanding official proclamations about 'evidence based policy'. The first report was theoretically driven in a manner we have not seen in this country for a long time. Using a systems analysis to show how the unintended consequences of policy interventions can lead to perverse outcomes, in this case the paralysis of front line child care staff as they retreat behind, or are overwhelmed by the demands of excessive bureaucracy, procedure manuals, and electronic data systems designed to 'share information' across services and interprofessional boundaries, to ensure compliance with the regulatory regime that has for twenty years been the main policy response to the politicians' demand that 'such a tragedy must never happen again'.

The political times move fast, and the more inclusive notion of 'safeguarding' as distinct from 'protection' is also now somewhat taboo, as a more or less familiar division between 'heavy end' child protection work (or tertiary and 'quartenary' prevention as Munro terms it) and 'early intervention' in the lives of vulnerable children is consolidated. The Coalition wants to distance itself from anything resembling 'big state' initiatives and Every Child Matters was just that, aiming to locate the needs of the most vulnerable children in our society within a comprehensive outcome focused policy agenda for all children, which Parton (2008) characterised as 'the preventative-surveillance state'.

In some respects Munro's critique of how child protection has evolved chimes well with current government ideology. She has been a trenchant critic of over-bureaucratisation, and calls for a return to front line child care practices based on professional judgement, an acceptance of occasional devastating failures to protect children, and a refusal of what she calls 'the charm of the counter-factual' - 'if the only the social worker had done $x$ then $y$ would never have happened'. This last tendency assumed a mantra like form in the wake of Lord Herbert Laming's original Victoria Climbié report, with his review team touring the country reminding us of the 'twelve missed opportunities' to save Victoria's life, from which we were supposed to learn how not to let it happen 
again. Munro is much wiser, and her second report makes it clear she understands that real world practice is an inherently uncertain, messy process always undertaken with incomplete data, especially when those who are supposed to be caring for children are systematically abusing them and know perfectly well that what they are doing is criminal and thus go to considerable, often intimidating lengths to throw others off the scent. Or as a colleague of one of us (AC) once said, 'Some people get together to have children they can abuse, because they need to do this'. Rather than retrospectively castigate individuals for their 'failures' Munro prefers to ask 'Why did competent, experienced, reasonable people not do the obvious?' Then she looks to the systemic conditions in which they were operating for an explanation. We talk about the child protection 'system' but previous reviews have signally failed to approach the task of reform with this in mind, preferring legalism (Louis Blom-Cooper in the 1980s) or technical-rational managerialism (Laming in 2003 and 2009).

\section{Challenges for the Munro reforms}

A first obstacle is that one suspects that Munro's vision was formed in the context of what now look like new Labour's years of plenty, and may struggle for air in the starved, chaotic public sector climate that awaits us. In public policy as in social work and therapeutic practice, timing can be everything. Children's services are suffering heavily as local authorities cope with the 'front loading' of the coalition's programme of cuts. Sure Start projects and children's centres, the prime sites of 'early intervention' (or 'early help' as Munro prefers to name it), are closing or being scaled down everywhere. Family support workers who do much of the face-to-face work with the most difficult families are being laid off and unqualified or student social workers are taking on more complex and risky cases. 'Targets and terror' culture probably did keep some of the most dysfunctional child protection services on task, and how some of these will perform now the terror factor is removed is anybody's guess.

One of the key messages of the Munro reforms is that the public expectation that the risks faced by children can be eradicated are unrealistic and aggravate the tendency towards blame by implying that, if a child is harmed, a professional must have been at fault. She argues that policymakers can collude with this belief, e.g., peppering national and local guidance with terms such as 'ensure' about matters which no person can realistically achieve (Munro, 2012). One of the effects of such societal expectations is that practitioners and managers must manage the anxieties that such expectations provoke. This is aggravated by wider trends in New Public Management, in which accountability is equated with documentation (Tsui and Cheung, 2004; Burton and van den Broek 2008). One of us (AW) spent time engaged in observing local authority children's teams just as the Munro review was beginning (Whittaker, 2011). One of the key aspects that appeared to be shaping everyday practice was a culture of pervasive accountability, in which 
many aspects of everyday practice were potentially subject to internal and external scrutiny. For example, one practitioner discussed a case that had attracted local media attention:

\begin{abstract}
Senior management had been made aware that there was some press involvement with the case and had gone to look at the file. I had literally been with the family all day and left late. When I arrived back the next day, I was told 'why isn't it on the system?' That put the wind up my sails and made me feel very anxious indeed. You do feel that you're being watched and your practice is being scrutinised. I do keep my notes up to date because it keeps them off my back. The fear drives you to that. (Whittaker, 2011; 490-1).
\end{abstract}

In such a climate, practitioners are tempted to use case records to engage in a form of pre-emptive exoneration to protect themselves from blame should decisions later turn out badly. This can serve to help practitioners to manage their anxieties, but at the cost of focusing on the child. A child psychiatrist who acted as an expert witness for court proceedings described receiving substantial local authority case records in the court bundle, but finding that they were predominantly about social workers describing and justifying their actions rather than describing the child's experiences.

So, what chance do these interventions by some very serious researchers and policy analysts have of making a difference? Is another destabilising eruption of the magnitude of the Victoria Climbié or Peter Connelly ('Baby P') cases just a matter of time? Consistent with her systemic principles, Munro's review process has tried to engage with a wider range of forces than previous reviews, including government's attitudes and responses towards instant mediatisation of selected child deaths. The exposure of News International's phone hacking policies may help in this respect if the 'freedom of the press' to mobilise the population's fondness for talion law in response to scandals involving sex and death is reined in, even just a little. In the Baby P case the Sun's million signature petition calling for the sacking of Sharon Shoesmith and other Haringey social work staff almost succeeded in its populist, mob rule objectives. Under intense pressure, the then secretary of state for Education Ed Balls appeared momentarily to endorse its aims at a televised press conference. It was an extraordinary lapse, a rupture in the function of the office of state as a last line of defence against vigilantism. Social workers who vaguely resembled those being targeted on the front pages were being verbally abused and spat on in the streets of North London. Shoesmith and her daughter were forced into hiding. In that instant Balls abandoned not a few individuals working for a beleaguered local authority in one of the country's most deprived areas, but a whole profession. Social workers are quite good at being understanding, but we know none who have forgiven Balls for this moment of 'failure'. 
However, scapegoating and blame cultures breed reciprocal blindness to complexity and social work, medicine, government, the news media and the general population all must look beyond each other for answers to why Britain has become the child abuse scandal capital of the world, and how the damage wrought by this status can be reversed. The notion of 'complexity' is itself part of the answer, but this is a hard argument to win with policy makers and governments who need, or believe they need, simple linear models of reality that generate easy-to-implement and monitor policy objectives.

As we go to press with this editorial government plans to enable the privatisation and outsourcing of child protection services are being fiercely debated in the public domain. Significant campaigns challenging these proposals are emerging, organised by among others 38 Degrees. Munro has clearly and simply voiced her opposition to the plans. 'It's a bad idea... It's the state's responsibility to protect children from maltreatment. It should not be delegated to a profit-making organisation' (Guardian, 2014). We do not have space here to rehearse in detail the arguments on this matter, but we would also put on record record our opposition to the proposals. Competition is the driving principle behind marketisation, but incentives for sector and interagency competition is the one thing we do not need in child protection work, which, as we have made clear elsewhere in this editorial, is a task made inherently difficult enough by its own internal conflicting forces. The protection of vulnerable children in our society is a social responsibility, for which we need optimum conditions of solidarity, free of dynamics that produce perverse incentives to intervene or not intervene on grounds other than those that are in children's best interests.

\section{Theoretical developments}

There have been some interesting developments in the form of recent theoretical work on child protection work and complexity, which proposes the idea of 'indicative' rather than predictive assessments of risk (Barlow and Scott, 2010). This notion responds to the lived reality of decision-making in contexts of inherent uncertainty where complex evolving systems such as families and their professional networks are the objects of analysis and intervention. Philosopher Sandra Mitchell has recently published an incisive account of why, and how, policy makers should embrace complexity (2010) and Munro references one of the more accessible and pragmatic contributions in this limited field of study, Jake Chapman's System Failure: Why Governments must learn to think differently, as well as frequently citing the 'complexity, uncertainty and anxiety' entailed by everyday decisions about children at risk.

Although these thinkers challenge the implicit positivism of the underlying social scientific world view that organises mainstream policy they are also 
inherently realist in orientation, in the sense that they assume the existence of an observable, describable psycho-social reality that exists independently of theory, ideology or social constructs. Child protection theorists have deployed various shades of social constructionism in their efforts to elaborate a grand theory of child maltreatment and our social responses to it, but a small dose of everyday practice as a child protection worker quickly immunises you against the sillier, relativising varieties of theory. One of the first cases that one of us (AC) handled began with a phone call from the local primary school, concerned about a six year old boy with a welt like bruise mark on his face. He told his teacher he had been playing with a belt, slapping it against the floor and it had flipped back into his face. I went to the school and he told me the same story, but after a few gentle questions he suddenly broke down in tears and said 'She has been hitting me.' At this moment I had to choke back my own tears. When I spoke with his mother, I was met with icy cold denial and we quickly reached an impasse. There was to be no parallel breakthrough with her. Fear for the small boy gripped me and I needed some steadying supervisory discussion not to over-react and seek to remove the child into emergency care. I walked home feeling invaded and frightened by the mother's suppressed hostility. And this kind of encounter is for beginners.

The Munro review is eloquent and forthright about the need to validate and support practice experience of this kind. She promotes the importance of professional 'reasoning' and errors of reasoning, but with an eye to the latest neuropsychological research showing that emotional and intuitive capacities are essential components of cognitive ability. Social work practice methods were once heavily influenced by psychoanalysis, before the profession tore itself apart in the 1970s in a civil war between political 'radicals' and social caseworkers. Psychoanalytic casework was overwhelmed because it had no sense of the political, or of radical traditions in psychoanalysis. Social work was emptied of any solid methodological basis for actually working with people. The 'century of the brain' has vindicated many of the clinically based insights of psychoanalysis, and sound scientific studies repeatedly show that differential early experience of caring relationships, emotional attunement, and parental 'mindfulness' predict later developmental patterns. The brain is plastic throughout life and develops, atrophies, and recovers in response to the emotional and relational qualities of a person's environment. These are important developments, laying to rest (in theory at least) decades of futile argument over whether social and psychological therapies are 'arts' or applied sciences. Cutting edge clinicians and researchers go further, arguing that lived experiences of social conditions provide the developmental context in which children ultimately thrive or fail. 'Communities shape experiences that change brains' is how American child psychiatrist Bruce Perry has expressed it. We are about ten years behind the USA in our efforts to inform family and early years policy with the best science. In 2000 the Institute for Medicine published From Neurons to Neighbourhoods, explicitly broaching the interlocking complexities of the biological sciences, child development 
research and the reflexive awareness of parents, professionals and policy makers to these findings:

.... one of the distinctive features of the science of early childhood development is the extent to which it evolves under the anxious and eager eyes of millions of families, policy makers and service providers who seek authoritative guidance as they address the challenges of promoting the health and well-being of young children... These scientific advances have generated a much deeper appreciation of the importance of early life experiences, as well as the inseparable and highly interactive influences of genetics and environment, on the development of the brain and the unfolding of human behaviour (Shonkoff and Phillips, 2000 p. 21).

The Allen Review attempted to emulate this ambitious early years public policy programme. Unhappily it remains wedded to the overly restrictive concept of evidence based practice promulgated by NICE in the new Labour years, in which a hierarchy of evidence types positions 'gold standard' randomised controlled trials as the only real game in town. Allen recommends that all funded early years programmes be evidenced based on such criteria and promotes nineteen examples, all but one of them originating from the USA. This is the familiar positivist category mistake, and a damaging one, which Munro implicitly identifies and challenges:

Evidence-based practice is sometimes used in a narrow sense to refer to using methods of helping service users that have research evidence of some degree of effectiveness. Here it is used in the broader sense of drawing on the best available evidence to inform practice at all stages of the work and of integrating that evidence with the social worker's own understanding of the family's values and preferences. It is not simply a case of taking an intervention of the shelf and applying it to a family (Munro, 2011, p.92)

At the level of high theory, Sandra Mitchell shows that the nature of different 'realities' cannot be deduced from first principles, or inferred from what we know about other ontological domains on which they depend. Realities are context bound and self-generating, and the evidence and research needed to guide interventions in any specific domain must be context relevant and discovered in their own right (Mitchell, 2009).

\section{Moving beyond assessment}

If the first bear trap awaiting the Munro Review is a public sector starved of resources, the second is a workforce that may not be adequate to the task of practising in the sophisticated, judgement based, emotionally resilient fashion she rightly advocates. Usually, more senior staff have never received the careful, emotionally intelligent casework supervision everyone is calling for, 
and its provision is something that requires learning from experience. Social workers in training are rarely schooled in any depth about how to undertake sustained, relationship-based interventions. A colleague of one of us (AC) who consulted to a children's service department in crisis said 'The only thing they know how to do, or think they should be doing, is assessment. They don't know how to move beyond this.' A recent ethnographic study of face-to-face encounters that social workers have with children and their families found that practitioners had varying levels of communication skills, playfulness and comfort with getting close to children. In those cases where practitioners did have these relational capacities, they were found to have developed deep and meaningful relationships but this was not consistent across practitioners (Ferguson, 2014). There is a drought of good literature in this area, and most social work educators have forgotten or lost interest in what they once knew, and never practice themselves. There is an archive of outstanding, if rather outdated methodological texts from the 1960s and 1970s that show rather than tell how to do the work, and at a certain point in their studies we introduce our post-graduate students to these. They fall on them hungrily, because they feel recognised in their own everyday experience. The science, the policy and the cultural climate may have changed but the nature of the work hasn't, or not that much.

The third trap lies in the wider cultural realm and the failures of political and professional 'containment' in response to child abuse scandals that have shaped the system Munro wants to deconstruct and refashion. However the story of what has, and has not been achieved across the decades, sometimes despite and sometimes because of these eruptions needs to be understood better if her work is to endure.

Shortly after the publication of the Jasmine Beckford report in 1985, one of a series of public inquiries into child deaths that dominated the middle of that decade, one of us (AC) took the decision as a senior social worker to return home the sibling of a child that had been received into care for suspected physical abuse. There was no obvious evidence that he had been maltreated as well. I (AC) thought I was exercising appropriate professional judgement. But then the sky (in the shape of senior management) almost fell in on me. The procedures had changed (or at least their interpretation had) and no such decisions were to be taken outside of a full child protection case conference. For a few hours I feared my head would roll. Fear was coursing through the system in the trail of the fierce criticism of social workers and social work delivered by the Inquiry team and the media, and inflexible proceduralisation of practice was one systemic response. Over the next two decades this process repeated itself many times. Munro cites work by Nigel Parton showing that the government's key statutory guidance document is 55 times longer now than it was in 1974. In 2005 Lord Laming noted that there were 13 procedures manuals bearing on child protection practice, but then delivered another 146 recommendations in his report for us to absorb. Incredulity and patronising allegations of bureaucratic thoughtlessness are an easy reaction, 
but the story is more complicated. Buried somewhere inside this proliferation of rules and strictures is a genuine effort to come to grips with vulnerable children's' need to be taken seriously, and for their circumstances to be acted upon. The surfacing of public and professional anxiety about child deaths and abuse also coincided with broader manifestations of Ulrich Beck's 'risk society'. The non-accidental death of a child known to children's service is a classic 'low probability - high consequence' event that poses profound political and policy dilemmas, similar to the processes that lead to the sudden imposition of new security regimes at airports following a terrorist alert. Actuarial methods of risk analysis became the fashion in child protection, as they did everywhere. As public sector 'modernisation' got under way in the 80s New Public Management methodologies impacted on social work which then experienced its own 'audit explosion'. Performance management and inspection regimes came and went, culminating with OFSTED who have not covered themselves in glory in this field, and were badly exposed during the Baby $\mathrm{P}$ crisis, having given Haringey a clean bill of health shortly before the case hit the headlines.

Munro wishes to row back from all of this, proposing that inspections be unannounced to avoid wasteful preparation, and concentrate attention on the quality of practice interventions rather than compliance with indicators and targets. This is all congruent with what the Coalition wants to hear. What is less evident is the manner in which the vast regulatory and audit superstructure we have come to accept has also served as a way of managing the profound social anxieties that child maltreatment poses for our society. Each year in Britain about 50 children, most of them under the age of four, are killed by their parents or immediate carers and many more are seriously injured. The system intervenes successfully to prevent 'significant harm', or worse, to thousands more. Although in fact the situation is probably much worse. In research published in the Lancet when, coincidentally, the Baby $\mathrm{P}$ crisis was at its peak, Christine Gilbert and colleagues reported that the actual prevalence of child maltreatment is likely to be more than ten times the rate that official figures suggest (Gilbert et al, 2009). They concluded that if the actual weight of need were visited on our services, they would instantly be overwhelmed. But, by and large the public and the media pay little attention to these 'routine' realities. The professional system does the job society appropriately assigns to it, and everyone (apart maybe from all those perpetrating and suffering abuse under the surface of the official statistics) can sleep at night safely protected from the knowledge that somewhere, not far from where each of us lives, babies and toddlers are being tortured, sexually violated, unthinkably neglected and sometimes murdered.

\section{Forming a public 'settlement'}

But from time to time the function of the system as a social container for these realities - but crucially also for the powerful anxieties they arouse in all of us bursts open, and society suffers a kind of panic attack as exceptionally 
primitive emotional dynamics are set in train. In the study mentioned earlier (Whittaker, 2011), one local authority manager offered an explanation for the public outcry that is provoked when the professional system fails to protect them from these realities:

... we're paid to stop the public from knowing that this sort of stuff goes on. So when the public find out about it, they get angry because they're denying that people do this stuff to children. And therefore if it becomes exposed they've got to blame somebody - 'how dare you invade my living-room at six o'clock when the news is on with this horrible stuff?'

Public Inquiries are the very particular, British mode of response to these eruptions, and evaluation of their meaning and contribution to overall social progress is not simple. Perhaps the most interesting case study is the 1987 Cleveland Inquiry. Shortly before the events that led up to it, one of us (AC) took on a case of suspected intra-familial abuse as a front line social worker. The social services child protection co-ordinator said to me 'Oh, I must attend that case conference - we don't get many of these cases'. A few months later, after hundreds of children in one city had been 'diagnosed' to be victims of sexual abuse in the space of a few weeks, the world had turned upside down. What was once mythologized as 'incest' and thought to be an unusual occurrence, except perhaps within certain closed rural communities, was now alleged to be commonplace, a repressed horror being enacted inside the haven of ordinary family homes up and down the country. Or was it? The Cleveland affair was actually a ferocious contest in which those diagnosing and disclosing abuse (albeit clumsily) were demonised as witch-finders and fantasists, and those rallying to the cause of the allegedly victimised parents were vilified as collaborators in the suppression of truth.

In the face of the 'dangerous knowledge' represented by the uncovering of widespread sexual abuse the turmoil quickly escaped the containing boundaries of the professional systems, and was propelled into the public domain. The Cleveland Public Inquiry was in effect charged with the task of deciding 'Who is right? What is the truth about intra-familial abuse?' and significant parts of the report are devoted to the problem of the frequent undecidability or indeterminacy of contested evidence and professional opinion in such cases. Nevertheless, the report did in effect adjudicate, concluding that in a significant majority of the Cleveland cases there were grounds to believe sexual abuse had taken place.

In an important sense our society never looked back, and Cleveland paved the way for corresponding social revolutions in other countries, most recently of course in Ireland and Belgium. Looked at in one way, it is remarkable how long this took; in another maybe not, such is the power of the agencies of repression - both psychological and institutional - involved. But after the deluge of Cleveland the reality of widespread child sexual abuse was largely assimilated into our idea of ourselves. The Inquiry process effected a lasting 
social 'settlement' in relation to a phenomenon that had always been there, but for which there had been no language, no symbolic system to help us name things, or think and act, a social manifestation of what psychoanalyst Christopher Bollas (1987) calls the 'unthought known'.

When allegations of organised Satanic and ritual abuse of children surfaced soon afterwards, the social turmoil was almost as acute. Child protection workers were accused of having departed their senses for the realms of horror comic fantasy. And we can say in retrospect that there may have been some validity to this view. But at the time, the truth once again was that people did not know what to believe - there was no available 'apparatus for thinking' about such claims, for distinguishing unimaginable truths from panic induced social fantasy. In the end the distinguished anthropologist commissioned to research the evidence for Satanic abuse concluded that there was not a single shred of forensic evidence supporting any of the more lurid claims of baby sacrifice, cannibalism, or the ritual drinking of the blood of sacrificed victims. But along the way, some important positive findings were established - about the nature and extent of organised and even ritualised abuse that advanced our capacity to protect children. But to my knowledge there has been no recurrence of allegations of Satanic abuse in this country. Again, the process of public deliberation achieved a 'settlement'.

So, what of the long succession of inquiries into the deaths of children? It was during the Victoria Climbié inquiry that it first occurred to me that the inquiry process itself, culminating in the publication of the report, might constitute an unrecognised process of public mourning. It is striking how in every one of these processes and accompanying media storm, the ordinary emotional registration of the death of the child is lost, or obscured behind the intense preoccupation with questions of blame, accountability, retribution, reconstruction of missed opportunities and so on.

The paradox is as follows: over the last forty years, the names of perhaps half a dozen of these same children have become inscribed in public memory and discourse, as well as in the often monumentally long and weighty reports of the inquiry into their deaths that sit in every academic and many public libraries. Beyond, somewhere out of public reach are the memories of all the others who have died similar deaths, but attained no such collective recognition. Like the tomb of the unknown soldier, does each of these inquiries and reports become the one that stands for the many? If so, it is also the case that we have so far refused to 'settle' this knowledge within ourselves. Something goes on and on being repeated as though we cannot, at the level of society, assimilate this knowledge into ourselves in the same way that we successfully did with sexual abuse following Cleveland.

Do we possess a symbolic framework to make sense of, mediate, child murder and torture in our society? We suspect not. In his article in this special issue, Cooper argues that various eruptions of new awareness in relation to 
child abuse were succeeded by a process in which public institutions were engaged in an effort at some sort of 'sense making', and that the evidence is these may have been broadly successful.

\section{The special issue}

In this special issue, we have attempted to cover a range of issues provoked by the Munro reforms. As editors, we are pleased with the quality and breadth of contribution in this special issue. Sue White begins by providing a progress report on developments since the Munro review. In her article, she argues that progress from the Munro review has been slow because it involves 'loosening the shackles' of central prescription. She argues that the traditional response within the child protection system has been to design complicated organisational structures that utilise technology to promote the illusion of control over a large volume of cases. Although Ofsted has changed its inspection methodology to focus upon outcomes, the dynamics of 'blame and shame' remain unaltered in a system that is driven by anxiety about child deaths and the fear of personal or organisational accountability. White argues that it is complex to establish what has changed as a result of the Munro review, as local authorities have provided differing responses to specific issues such as assessment timescales, including choosing to retain the shackles of central targets or designing their own. However, there has been important conceptual changes in which previous contests have resulted in a settlement in which face to face work with children and families has been recognised. Rather than looking to engineering metaphors and 'seductive proxies for quality' such as timescales and targets, we should be looking to gardening metaphors to understand how systems design can be more organic and aim at building trust and supporting the front-line professional task.

The Munro review argues that one of the key drivers of the child protection system in England is the public reaction when a child is harmed (Munro, 2010). The article by Cooper provides an historical analysis of 'moral panics' over child maltreatment over the last forty years that gives depth to this analysis. Cooper argues that the child protection system has two primary tasks, an explicit task to protect children and a covert task to protect the public from knowing about the existence of child maltreatment. Moral panics occur when the professional systems are unable to contain 'dangerous knowledge' about child abuse and the debates are propelled into the public sphere where settlement is sought through public inquiries and other social mechanisms. Whilst this achieves settlement in some epistemologically contested areas, such as the existence of ritual abuse and the debates about recovered memories, the emotionally indigestible and anxiety-provoking nature of child deaths means that the problem is difficult to contain within professional systems and is recurrently projected back into the public sphere. It is suggested that this may be associated with the absence of a secure symbolic framework or discourse, which is in turn associated with difficulties in public mourning rituals that are not addressed by the public inquiry process. The 
Munro review has argued that one of the problems with the present child protection system is that its capacity to protect children is idealised in unrealistic ways and the article concludes that adopting a tragic perspective to child maltreatment is an importance means of challenging this.

The Munro Review offers an analysis that strives to address the neglect of the emotional dimension in child protection work. This aspect is discussed in depth in an extended article by Pam Trevithick, which discusses a number of key issues underpinning this emotional dimension. Trevithick begins by examining what is meant by a number of key terms, including emotions, feelings, affect, attunement and empathy. The role of emotions in the tensions between intuitive reasoning and logical thinking is then explored together with the part played by conscious and unconscious elements in the formation of professional judgements. She then examines how rigid forms of managerialism neglect the role of emotions in professional decision making. In a final section, a persuasive argument is presented for the need to 'humanise' managerialism in a way that recognises the importance of relationships and embed an 'emotional dimension' that integrates logical thinking and intuitive reasoning.

Although blame is a central theme in the analysis offered by the Munro Review, there is no explicit reference to the dynamics of scapegoating or exploration of the reasons why they are difficult to resist or overcome. This is the central thesis of an article by Gillian Ruch, Amanda Lees and Jane Prichard, which presents a critical analysis of the concept of scapegoating. The article outlines how the dimensions of scapegoating behaviour have been discussed in the literature and examines how organisational conditions can encourage scapegoating. The impact in organisational settings is explored and key models for both understanding and countering scapegoating processes are examined. The article concludes that greater understandings of the processes of scapegoating are needed if the Munro reforms are to have their full impact.

The Working Together guidance has been revised in the light of the Munro review, shortening it from 390 pages to 97 pages. In the article by Paul Dugmore, this revised guidance is examined using critical discourse analysis to understand the underlying messages within a wider policy context and to examine how congruent they are with the spirit of the Munro reforms. Dugmore identifies a clear discourse of localism but little evidence that this is desired at local level. He highlights the tensions between the portrayals by political leaders of social workers as 'robotic bureaucrats' with the increasingly proceduralised approaches to child protection that have been the traditional government response to high profile child deaths. He argues that the language and style used in the guidance has the effect of being read not as a set of arguments, but as a set of assertions or exhortations. Whilst the guidance formally acknowledges at one point that risk cannot eliminated, Dugmore argues that the dominant way in which child protection practice is 
presented is as a series of simple 'step by step' instructions. Practitioners simply need to follow these steps, aided by supervision from their manager that enables them to critically reflect upon their practice. He concludes that many practitioners will struggle to recognize this vision of everyday child protection practice and that issues such as parental hostility, lack of cooperation and agency neglect need to be address if these emotional realities are not to be simply sanitised in the guidance.

One of the cornerstones for promoting good practice identified by the Munro review is good supervision. This has been central to social work practice and the article by Anna Harvey and Fiona Henderson presents a model of reflective supervision that is informed by psychoanalytic concepts. The article argues for going beyond a simplistic dualism where supervision is regarded as either nurturing or controlling. Using a case study of a newly qualified social worker, Harvey and Henderson demonstrate how supervision can act as a thinking space to explore emotional processes in the worker-family relationship, in relationships with the organisation and within the practitionersupervisor relationship. By doing this, supervision can enable practitioners to engage with the complexities of child protection practice and understand the powerful and unsettling emotions that can be evoked.

The Munro Review identified a number of projects as examples of promising practice. One example is the Family Drug and Alcohol Court (FDAC), which was identified as providing quicker access to substance misuse services for parents and a wider range of support services for other problems, which resulted in fewer parents misusing by the end of care proceedings because they engaged with services for longer, resulting in more children returning home (Munro, 2010). This service is discussed in depth in the article by Steve Bambrough, Mike Shaw and Sophie Kershaw, three key professionals who have been instrumental in developing the service. From its outset, the FDAC service aims to make a decision about whether a child is to be returned home by the time the child is 6 months ago to fit in with the child's developmental timescales. The authors describe how this can feel like a 'dictatorship of the children's timescales', which can require a brutally realistic approach to the hope invested in change.

The child-centred nature of timescales has taken centre stage in the Norgrove report, which was published shortly after the Munro Review. In apparent contrast to the rigid timescales eschewed by the Munro reforms, the Norgrove report recommended that the time limit for the completion of care and supervision proceedings should be set at 26 weeks (Family Justice Review, 2011). This is now incorporated into legislation by the 2014 Children and Families Act and has had a significant impact on everyday practice in child protection. At first glance, this would appear to be a straightforward struggle between the forces of managerialism versus greater scope for professional judgment. However, the article by Jonathan Dickens and Chris Beckett argues that this oversimplifies the debate and identify that concern about court delay 
was originally raised by clinicians who were concerned about the impact on children. They explore how the anxieties involved in making 'Solomonic judgements' can lead to a temptation to defer decisions even when the new information is highly unlikely to make decisions more clear cut. Such quest for certainty on the part of the adults can ironically prolong the uncertainty for the child. They conclude that the pilot project offers hope that it is possible to have decisions that are both quick and thorough, though it is necessary to recognise the anxiety provoked by such decisions and have adequate support systems in place.

\section{Conclusion}

When forming a judgment about how the Munro reforms are influencing the child protection system, an appropriate response may be that reputedly offered by the Chinese foreign minister Zhou Enlai when asked about the impact of the French Revolution - it's too early to say. Previous reforms have been judged by the changes in policy and legislation that they have introduced, more than changes in frontline practice. The Munro reforms are more difficult to measure because policy itself, in the form of prescriptive guidance and procedures, is identified as part of the problem rather than the solution. The second loop system that Munro proposes questions the appropriateness of the targets set centrally and challenges the taken-forgranted nature of the policy implementation process. Such a theoretical framework is more radical than is often appreciated and has the potential to offer a new approach to the policy making process. Whether this potential will be taken up or whether there will 'business as usual' remains to be seen.

At the outer boundaries of the 'system complexity' Munro and others are trying to instate within a new policy analysis paradigm, lurk more or less invariant and possibly intractable dilemmas of human nature: how to contain our desire for sexual and social domination of children and other adults, how to break the inter-generational transmission of psychic damage, and how to defeat death. Thus a final big bear trap into which the review might tumble is a further explosion of public resentment at being faced with knowledge of these truths, should another tragedy escape the confines of the professional system. In the eyes of many people who work in child protection the NSPCC made an idiot of itself a few years ago by campaigning to 'end child abuse' by 2010. The truth is that despite all the sturm und drang surrounding this work, we have hardly scratched the veneer of civilised behaviour that obscures the truth from view. We could be achieving much, much more, and the real revolution still to be triggered is to genuinely see the world through the eyes of the child, and then design policy and practice to match. This is a challenge to the adult narcissism that permeates our political processes, and indeed all of us. With their somewhat less lofty ambitions to root policy in good science and theory rather than outdated paradigms of social behaviour and the scapegoating of 'incompetence', Munro and her colleagues are setting a new standard. How it will play is uncertain, but then that's the nature of complexity. 


\section{References}

Barlow, J. with Scott, J. (2010) Safeguarding in the 21st Century - Where to now? Totnes; Research in Practice.

Bauman Z. (1992) Mortality, immortality and other life strategies, Cambridge. Policy Press

Bollas, C. (1987) The shadow of the object: Psychoanalysis of the unthought known. Columbia University Press.

Burton, J. \& van den Broek, D., (2009) Accountable and Countable:

Information Management Systems and the Bureaucratization of Social Work. British Journal of Social Work, 39, pp.1326-1342.

Laming, Lord, (2003) The Victoria Climbié Inquiry. Cm. 5730, London: The Stationery Office.

Laming, Lord, (2009) The protection of children in England: A progress report. Vol. 330., London: The Stationery Office.

Family Justice Review, (2011) Family Justice Review: Final Report, London: The Stationery Office. Available at:

https://www.gov.uk/government/uploads/system/uploads/attachment_data/file/ 217343/family-justice-review-final-report.pdf.

Ferguson, H., (2014) What social workers do in performing child protection work: evidence from research into face-to-face practice. Child \& Family Social Work. Available at: http://doi.wiley.com/10.1111/cfs.12142 [Accessed March 25, 2014].

Gilbert, R., Spatz Widom, C., Browne, K., Fergusson, D., Webb, E., and Janson, S. (2009) Burden and consequences of child maltreatment in highincome countries. The Lancet, 373, (9657), pp. 68-81). DOI: 10.1016/S01406736(08)61706-7.

The Guardian, 'Privatise child protection services, Department for Education proposes' , 16.05.14.

Hope B (2011) All in a Day's Work, London. Hodder and Stoughton

Mitchell, S. (2009). Unsimple truths: Science, complexity, and policy. Chicago: University of Chicago 
Munro, E., (2011) The Munro Review of Child Protection: Final Report, a child-centred system. Vol. 8062, London: The Stationery Office.

Munro, E., (2012) Progress report: Moving towards a child centred system. London: The Stationery Office.

Parton, Nigel (2008) “The 'Change for Children' programme in England: Towards the "preventive-surveillance state." Journal of Law and Society 35(1): 166-87.

Shonkoff, J. P., \& Phillips, D. A. (Eds.). (2000). From neurons to neighborhoods: The science of early childhood development. National Research Council, Committee on Integrating the Science of Early Childhood Development.

Tsui, M. \& Cheung, F., (2004) Gone with the Wind: The Impacts of Managerialism on Human Services. British Journal of Social Work, 34(3), pp.437-442.

Whittaker, A. (2011) "Social defences and organisational culture in a local authority child protection setting: Challenges for the Munro Review?" Journal of Social Work Practice 25(4): 481-95. 